\title{
A imagem dos jesuítas através de recursos coesivos no discurso antijesuíta
}

\section{The image of Jesuits through Cohesive Resources in Anti-Jesuit Discourse}

\author{
DALibor Horváth [dalibor.horvath@centrum.cz] \\ Univerzita Palackého v Olomouci, República Checa
}

\begin{abstract}
RESUMO
Neste artigo aprofundaremos os estudos do discurso antijesuíta, concebidos não apenas como aglomerados de uma exposição escrita, mas como macrotextos, ou seja, como totalidade orgânica apoiada em linhas de coerência textual, ideológica e histórica. Analisaremos alguns recursos coesivos de diferentes textos anitijesuítas que circulavam em Portugal desde o século XVI e, à luz de novos estudos sobre recursos coesivos e a sua influência no discurso atual, de modo minucioso, interpretaremos o discurso antijesuíta. Com ela, por meio de algumas teorias da coesão textual de Irandé Antunes, esclareceremos a prática discursiva de alguns críticos desta ordem religiosa, reparando-nos no uso de palavras e expressões que eles utilizavam com o objetivo de persuadir. Revisaremos o discurso antijesuíta para extrairmos algumas conclusões acerca do que pode resultar desta revisão em termos de recursos coesivos, analisando a imagem dos jesuítas portugueses.
\end{abstract}

\section{Palavras-Chave}

Jesuítas; recursos coesivos; substituição; coesão; repetição; discurso; portugueses; antijesuíta

\section{Abstract}

This article deals with the importance of cohesive resources in anti-Jesuit discourse. Its aim is to deepen the meanings of the anti-Jesuit texts, conceived not only as clusters of a written exposition, but as macro texts, that is, as organic totality supported by lines of thematic and ideological coherence, underlining the importance of repetition and substitution of lexical and grammatical items. The article analyses the text cohesion which arises from semantic relationships between grammar and words, focused on recurrence and substitution of language resources. Through the analysis, the article applies theories of Irandé Antunes to anti-Jesuit discourse and the study also focuses on discursive practices of some critics of Jesuits. An image of the Jesuits is composed and it is referred to the nature of the individual linguistic resources.

\section{KEYWORDS}

Jesuits; cohesive resources; substitution; cohesion; repetition; discourse; Portuguese; anti-Jesuit

RECEBIDO 2021-02-15; ACEITE 2021-06-01 


\section{A metodologia da investigação}

Analisaremos a coesão textual de alguns fragmentos dos livros Retrato dos Jesuitas (1761) e Centinela contra Jesuitas (1845) onde aparecem diferentes textos do discurso antijesuíta em Portugal. Além disso, inspirando-se no quadro da coesão textual da linguista brasileira Irandé Antunes (Antunes 2005), aplicaremos algumas das suas teorias em alguns textos antijesuítas dos livros citados acima, dedicando-nos, sobretudo, à repetição e à substituição que matizam a parte linguística de qualquer discurso. Dentro do conceito da repetição, nos textos antijesuítas, analisaremos o uso de paráfrases (reformulação da mesma informação) e de paralelismos (consiste na repetição de ideias ou de construções sintáticas). Nos estudos sobre a substituição, analisaremos como este recurso abarca certas reiterações, trocando palavras por pronomes, advérbios, sinónimos ou hiperónimos que tornam frases antijesuítas mais sincopadas. Como algumas retomadas de termos (anáforas, catáforas, pronomes possessivos ou conjunções múltiplas de intensidade) pertencem aos meios linguísticos de aplicação textual geral, não podem ser consideras sendo certas caraterísticas dos textos antijesuítas. Por outro lado, a repetição destas retomadas de termos podem indicar a prática discursiva na época. No âmbito da coesão textual de Irandé Antunes, revelaremos alguns recursos coesivos no discurso antijesuíta e analisaremos a imagem dos inacianos portugueses, sendo a repetição e a substituição de palavras que, em nossa opinião, são dois promotores que, como veremos, intensificam a parte emocional do discurso antijesuíta.

\section{A parte introdutória}

Irandé Antunes completa as teorias de Halliday e Hasan (Halliday e Hasan 1976), sublinhando que a coesão depende da identidade semântica entre o referente pressuposto e a pró-forma que indica a sua presença no espaço, quer seja o texto, quer seja a situação (Antunes 2005: 48). Mas Halliday e Hasan não são os únicos linguistas que inspiram Irandé Antunes, são também algumas teorias de Leonor Lopes Fávero que percebe a coesão como uma manifestação microtextual e sublinha que essa mesma «refere aos modos como os componentes do universo textual, isto é, as palavras que ouvimos ou vemos estão ligadas entre si dentro de uma sequência» (Fávero 1991: 10). E é também a linguista Ingedore Villaça Koch que inspira Irandé Antunes na formação do quadro da coesão textual (Antunes 2005: 51). Koch e Fávero dividem três tipos de coesão (Fávero e Koch 1985): lexical (reiteração ou substituição), referencial e sequencial (por conexão ou temporal) (Fávero 1991: 17). É Fávero que descreve cinco tipos de reiteração (repetição das mesmas expressões no texto): sinónimos, hiperónimos e hipónimos, repetição do mesmo termo, expressões nominais (um novo termo retoma uma palavra utilizada no texto) e nomes genéricos (expressões usadas numa certa cultura e todos conhecem o seu significado) (Fávero 1991: 23-25). A parte sequencial, segundo Fávero, são mecanismos coesivos que fazem caminhar o fluxo informacional e podem fazer parte da sequenciação temporal (o texto é coeso e coerente através de condições conceptuais sobre a ordenação e localização) e da sequenciação por conexão (tudo está relacionado no texto em que há operadores do tipo lógico ou operadores discursivos). A sequenciação temporal a linguista divide em quatro partes: a ordenação linear dos elementos (expressões usadas de certa forma), expressões que balizam a ordenação ou continuação de certas sequencias temporais 
(exemplo: primeiro isto, depois outra coisa), partículas temporais (relativo ao tempo), correlação dos tempos verbais (exemplo: o uso de conjuntivo). Dentro da sequenciação por conexão encontramos certos operadores do tipo lógico: disjunção (proposições por meio de um conector), condicionalidade (uma frase condiciona outra), medição (fazem parte da condicionalidade de forma didática), complementação (há duas proposições e uma delas complementa o sentido), restrição (há duas proposições e uma limita outra) a quebra da coesão (frases inacabadas, concordância incorreta, etc) (Fávero 1991: 33-40).

Nesta mesma linha, temos ainda a coerência que facilita a progressão sistemática do texto e abrange subáreas que são indispensáveis na sua produção: a coesão lexical (repetição de itens lexicais que possuem o mesmo referente), a referenciação (utiliza-se para fazer menção a termos anteriormente mencionados), a substituição (colocação de um item no lugar de outro), a conjunção (propulsa a linearidade e o sentido das orações coordenadas e subordinadas) e a elisão (omissão de um item recuperável pelo contexto e representa uma ideia de sujeito oculto no enunciado). E é, sem dúvida, na coerência que ouvintes ou leitores atingem a sua compreensão da estrutura do texto cuja base se centra na duração contínua de sentidos entre os conhecimentos ativados pelas expressões do texto. Melhor dizendo: esta capacidade relaciona-se com sentido do texto e é indispensável na sua produção, subordinada à ordem dos argumentos e das ideias.

Ligada à coesão, a coerência representa o ponto de chegada de uma compreensão do texto e, como sublinha Ingedore Villaça Koch, para haver coerência «é preciso que haja a possibilidade de estabelecer no texto alguma forma de unidade ou relação entre os seus elementos» (Koch 2014: 22). Lembremo-nos de que, no texto, é a coerência que se mostra em forma de sentido e de enunciados colocados por ordem para ser compreensíveis para ouvintes e leitores, ligando bem todos os elementos gramaticais e lexicais. Além disso, a coerência, vista de forma macrotextual, segundo Leonor Lopes Fávero, refere «aos modos como os componentes do universo textual, isto é, os conceitos e as relações subjacentes ao texto de superfície se unem numa configuração» (Fávero 1991: 10). Irandé Antunes declara que a coerência significa «construir um texto, capaz de funcionar sociocomunicativamente num contexto específico, uma operação de natureza também lexical e gramatical» (Antunes 2005: 93). E, para ficar bem claro, os estudos da coesão são importantes para estabelecer ligação entre elementos sintáticos e léxico-morfológicos, fazendo parte da unidade de sentido, enquanto a coerência facilita a compreensão do sentido do texto, dependendo, às vezes, do contexto do que no próprio texto.

\section{A coesão textual no discurso antijesuíta em Portugal}

\subsection{Os recursos da repetição no discurso antijesuíta}

A coesão textual, segundo Irandé Antunes, se expressa pelas relações de reiteração, associação e conexão (Antunes 2005: 50). Além disso, essas relações, segundo Antunes, podem ocorrer através de várias ações que a linguista chama procedimentos e esses se manifestam em diferentes recursos, limitando-se a apresentar a coesão do texto como três campos: relações textuais, procedimentos e recursos (Antunes 2005: 51). A coesão textual, segundo a linguista, só pode acontecer a partir de relações textuais e de alguns conceitos que amoldam o caráter do texto. É, por exemplo, a reiteração 
que aparece na coesão, retomando alguns segmentos do texto que «asseguram a necessária continuidade de seu fluxo» (Antunes 2005: 52), sendo pronomes ou sinónimos que melhor podem caracterizar a substituição de expressões. Outro conceito de relações textuais é a associação que é uma certa ligação de diferentes palavras de um mesmo campo semântico, fazendo que todo texto seja «necessariamente marcado por uma unidade temática, isto é, pela concentração em um único tema» (Antunes 2005: 54). O último conceito é a conexão que é importante para estabelecer uma relação semântica entre várias frases ligadas a outras por coordenação ou subordinação com as quais formam frases complexas, realizando-se, como sublinha Antunes, por meio de preposições, conjunções, locuções ou expressões de valor circunstancial (Antunes 2005: 55). Deles podemos analisar a coesão de qualquer texto que retoma, repete e liga sentidos entre várias expressões e, como é sabido, através de conectores, estabelece relações semânticas entre frases e parágrafos.

$\mathrm{O}$ acolhimento dos conceitos de relações textuais, que entretanto se compreendem como «uma rede de relações que se criam no texto, enlaçam-se no quadro figurativo do laço entre eles» (Antunes 2005: 52). Mas para se realizarem, relações textuais, como sublinha Antunes, precisam de alguns procedimentos coesivos como a repetição, a substituição, a seleção lexical ou a conexão sintático-semântica. De facto, na ideia dos procedimentos não deixa de existir a compreensão de aspetos complexos de qualquer texto. É decerto que, como veremos, estes procedimentos coesivos aparecem também no discurso antijesuíta e chegam a alcançar o estatuto de afirmação, embora não todos estejam presentes. Por outro lado, os recursos coesivos são certos atos pelos quais os procedimentos se manifestam, sendo, segundo Antunes, certas «operações de repetir, de substituir, de usar palavras semanticamente próximas, de usar uma conjunção ou um outro tipo qualquer de conectivo» (Antunes 2005: 60).

O que sucede com os procedimentos coesivos não se afasta do campo semântico em que o texto se produz. Na medida em que a cada procedimento corresponde a algum recurso, a tendência será para ver neles uma coerência textual, em termos de repetição e de substituição (lexicais ou gramaticais). A primeira deles, a repetição, abrange os recursos como a paráfrase (enunciados que reformulam a mesma informação de outros enunciados), o paralelismo (a uma unidade semântica corresponde uma estrutura gramatical) e a repetição de palavras ou expressões (exprime aquilo que foi dito antes). A segunda, a substituição, abarca um certo tipo de reiteração, trocando palavras por pronomes, advérbios, sinónimos ou hiperónimos que tornam frases mais sincopadas. Num plano mais geral, pode ainda colher-se a ideia que dá a linguista brasileira Irandé Antunes na teoria sobre os recursos de repetição, mostrando a importância da paráfrase e do paralelismo na coesão textual. Um dos aspetos que requer atenção é, desde logo, a paráfrase que várias vezes aparece no discurso, sendo um enunciado que reformula, com fins explicativos, a mesma informação de outro enunciado que, no caso dos textos críticos, torna a formular a linguagem antijesuíta. A paráfrase é, como sublinha Antunes, «uma operação de reformulação, de dizer o mesmo de outro jeito" (Antunes 2005: 62), utilizando expressões como a saber, ou seja, isto é, quer dizer, em outras palavras, reformulando o mesmo item, ligando, através de nexos coesivos, dois segmentos textuais ditos com palavras diferentes. Vejamos pois o nexo coesivo que se utiliza nos textos antijesuítas para reformular a ideia anterior:

Com esta Declaração nos fazem os Jesuitas passar aos olhos de todo o mundo não só como complices [sic], mas tambem [sic] como unicos [sic] auctores [sic] desta odiosa versão (de que eles são 
culpados) contra dois pontos principais, da Religião Christãa [sic] cujo uzo [sic] e pratica [sic] se tinha conservado sempre neste Reino, a saber: o governo Episcopal, e o Sacramento da Confirmação [...]. (Rodrigues 1761: 160)

Se os Jesuitas forem supportados [sic] mais tempo: se por vossa benignidade os deixares lançar raizes neste Reino, devemos esperar que o povo ha de [sic] ficar Jesuita, quero dizer, ha de [sic] deixar de ser Francez [sic], ha de [sic] desprezar os costumes Francezes [sic] [...]. (Rodrigues 1761: 28)

Pelo que entre nós a menor obrigação, ou o mais baixo grao [sic] de obediencia [sic], consiste em fazer o que se nos manda; ou, para o dizer melhor, não há obediencia [sic] quando aquelle [sic], que executa o que se lhe mandou, não conforma interiormente a sua vontade, ou o seu juizo com o pensamento, ou sentir de quem o manda. (Rodrigues 1761: 239)

Invocada pelos adversos da ordem, a imagem dos jesuítas acaba por ser influenciada no quadro do léxico, remetendo o julgamento dos inacianos para o domínio da linguística: a paráfrase intensifica a crítica e a postura do autor, esclarecendo e explicando a mesma informação com outras palavras. Além disso, a paráfrase enlaça-se no quadro figurativo da enunciação. Nele existem duas formas do discurso: o discurso de caráter dialogal em que há duas figuras (uma a fonte e outra a meta da enunciação, enquanto na posição de interlocutores as duas figuras são protagonistas da enunciação) e o monólogo.

Outro recurso da repetição é o paralelismo que consiste na repetição de ideias e de construções sintáticas em determinadas frases, sendo aquilo que «leva a prever que os elementos coordenados entre si apresentem a mesma estrutura gramatical» (Antunes 2005: 64). No livro Retrato dos Jesuitas, podemos ver vários exemplos do paralelismo que tem também um caráter estilístico:

[...] mas elle [sic] mesmo he [sic] quem me obriga a dizer a Vossa Excellencias, que se deve conceder a licença para que saia á [sic] luz, e se veja o Retrato de hum [sic] mal, que ninguem [sic] deve desconhecer. (Rodrigues 1761: ssi)

Os elementos coordenados para que saia á [sic] luz, e se veja o Retrato de hum [sic] mal apresentam a mesma estrutura sintática, exprimindo também certa harmonia que, como sublinha Antunes, «deixa o enunciado numa simetria sintática que é por si só articuladora» (Antunes 2005: 64). Além disso, dentro do conceito do paralelismo, encontramos um designativo das locuções e conjunções coordenativas compostas por dois elementos constituídos por uma ou mais palavras, utilizando expressões como não tanto....quanto, não só....mas também, etc.:

Mostravam-se estes homens [os Jesuitas] tão apaixonados, e atrevidos, que eram insuportáveis [sic], continunado em enganar os meus vassalos [sic], fazer seus conveticulos, não tanto para vencer, e converter os de Religião contraria, quanto para tomar pé, e a autoridade em o meu Estado; e enriquecerse [sic] e augmentarse [sic] á [sic] custa de cada hum [sic]. (Rodrigues 1761: 53)

[...] que todo o mundo se ha de salvar sem excepção....maxima condemnada, que se opõem [sic] tanto ás [sic] palavras de Jesus Christo [sic], como á [sic] Tradição da Igreja. Fomentam o vicio, 
promettendo [sic] impunidade: e o ensinam nos Escritos, que publicam em lingua [sic] vulgar [...]. (Rodrigues 1761: 187)

Com esta Declaração nos fazem os Jesuitas passar aos olhos de todo o mundo não só como complices [sic], mas tambem [sic] como unicos [sic] auctores [sic] desta odiosa versão (de que eles são culpados) [...]. (Rodrigues 1761: 160)

$\mathrm{Na}$ linha do paralelismo, podemos ver como a mesma estrutura sintática, dentro do processo correlativo de adição, dá ao enunciado uma harmonia e assim não perde a sua compreensibilidade. Outro tipo do paralelismo acontece com assim chamada série enumerativa cujos segmentos fazem parte de uma disposição sintática simultânea:

[...] foi a origem de todo o odio, perseguição, e furor, com que estes Religiosos se levantaram contra mim, e ao mesmo tempo contra a minha dignidade: porque vendo elles [sic] que daquelle [sic] modo se punham limites a esta impetuosidade, como que amontoavam riquezas tão grandes [...]. (Rodrigues 1761: 206)

No fragmento da carta do bispo da Povoa dos Anjos na América, vemos como a série de complementos esclarece a postura do autor, enumerando as expressões que levaram o texto ao campo do antijesuitismo, mostrando certa crítica dos inacianos nas terras ultramarinas. Ainda no plano da simetria sintática das estruturas linguísticas, e partindo do conceito dos recursos da repetição, podemos sublinhar que além dos substantivos que aparecem em séries enumerativas (esses não levam determinantes), nos textos antijesuítas, encontramos também uma enumeração de adjetivos, particípios passados ou gerúndios que reforçam o caráter persuasivo do discurso, no sentido de definir os jesuítas e os objetos da crítica, relativamente à função coesiva:

Jesuitas reconhecidos enganadores, despojados de todos os seus bens, desnaturalizados, correndo os mares, errantes na Italia, buscando pão á [sic] custa dos Vassalos [sic] do Papa, detrahidos [sic] em toda a Europa”. O que lhes succedeo [sic] em Portugal, póde [sic] succederlhes [sic] nos outros Reinos. (Rodrigues 1761: 97)

Outro tipo do paralelismo evocado a propósito da repetição é aquele que utiliza certos verbos para reforçar o seu caráter persuasivo, figurando no discurso antijesuíta e dando mais força à ordenação lógica e sequencial das palavras relacionadas. Vejamos, por exemplo, o uso dos verbos autorizar e justificar que têm ligação com outros verbos do texto:

Em fim isto he [sic] o que mostra a sua Moral deshumana, que auctoriza [sic], e justifica o matar, dar veneno, commetter [sic] assassinio [sic], parricidio[ sic], e regicidio [sic] em todos os casos, em que se trata de preservar de algum perigo a propria [sic] vida, honra, ou fazenda, vingar dos males, ou afrontas, que se tem soffrido [sic]. (Rodrigues 1761: ix)

Assistimos a uma enumeração das palavras que complementam os verbos transitivos autorizar e justificar, sendo uma série das palavras que sublinham o caráter dos jesuítas e apresentando-a com 
as expressões como dar veneno ou commetter [sic] assassinio [sic], parricidio [sic], e regicidio [sic] em todos os casos se relacionam com os verbos de caráter moral e emocional-afetivo para persuadir os leitores. Além disso, no texto antijesuíta, vemos uma enumeração dos substantivos como vida, honra, ou fazenda, formando uma disposição sintática paralela de caráter emocional-afetivo com a qual o autor exprime a sua postura para com os jesuítas e, ao mesmo tempo, tenta convencer ouvintes e leitores.

Os textos antijesuítas chegam a acolher várias repetições lexicais, em sintonia com a teoria de recursos repetitivos que transparecem no discurso da época. Vimos já como a paráfrase se verifica nos textos antijesuítas. E revelamos também como o paralelismo se manifesta nas unidades semânticas que correspondem à mesma estrutura gramatical. Mas, a este respeito, nos textos antijesuítas, aparece outro conceito repetitivo que intensifica a crítica: a repetição propriamente dita, correspondida, como sublinha Antunes, a «ação de voltar ao que foi dito antes pelo recurso de fazer reaparecer uma unidade que já ocorreu previamente» (Antunes 2005: 71). Trata-se de um recurso estilístico que consiste em repetir as mesmas palavras, expressões ou frases, sendo um recurso textual significativo em que há certas continuidades exigidas pela coerência. Vejamos pois como a repetição de expressões desempenha uma função persuasiva, correspondendo à ênfase como recurso estilístico que exprime certos sentimentos:

Certamente que, se os Jesuitas fossesm culpados de todos os males, que este homem de bem o [Reitor da Universidade] lhe imputa, teriam razão de lhes fazer peior [sic], do que privallos [sic] da união da Universidade [...] Se os Jesuitas sam [sic] culpados de todos os males, que o nosso Apologista lhes argue, elles mesmos confessam que teriamos razão de lhe fazer peior [sic], do que privallos [sic] da união com a Universidade de Pariz [... Nota. Immediatamente antes das palavras, que a Universidade aqui nota, tinham os Jesuitas feito huma [sic] lista dos males, que o Apologista da Universidade lhes tinhas arguido. E todos estes males sam [sic] os que a Universidade offrece [sic] verificar diante de todos os Prelados de França, e de Parlamento. (Rodrigues 1761: 189)

Sei que huma [sic] multidão de factos contra tudo o que ha [sic] de sagrado, e profano, contra tantas Universidades, tantos Mosteiros, tantas Casas, tantos Palacios [sic], tantas Republicas [sic], tantos Reinos, contra o Estado, e contra a Igreja, contra Deos [sic], e contra Cesar [sic], nos deve encher, e ocupar de pasmo [...]. (Rodrigues 1761: iii)

Se os Jesuitas forem supportados [sic] mais tempo: se por vossa benignidade os deixares lançar raizes neste Reino, devemos esperar que o povo ha de [sic] ficar Jesuita, quero dizer, ha de deixar [sic] de ser Francez [sic], ha de [sic] desprezar os costumes Francezes [sic]...»(Rodrigues 1761: 28)

No primeiro fragmento da carta que citámos, podemos ver como as expressões culpados de todos os males manifestam o efeito enfático produzido pela repetição de palavras. Com ela, o autor exprime sentimentos, utilizando a palavra mal que tem também um caráter axiológico em que todos podem decifrar o seu significado negativo. No segundo fragmento, escrito por um monge da Congregação de São Bento em Portugal, podemos ver outro efeito enfático do quantificador existencial tanto e da preposição contra, os dois intensificam a parte emocional do discurso, aumentando ainda mais o problema do antijesuitismo e sublinhando a sua amplitude 
na sociedade portuguesa da época. O terceiro fragmento, escrito por alguns párocos franceses, utiliza a construção com valor modal de intenção sobre o futuro haver de em que, em nossa opinião, se valoriza o conceito do medo psicológico que, durante séculos, foi objeto de influência social, em formas de abuso e exegese crítica. O medo de perder a naturalidade e os hábitos esclarece a intenção do autor que, através da construção com valor modal, exprime a sua postura para com a Companhia de Jesus e, por meio da repetição, faz esforços para persuadir ouvintes e leitores.

Outra repetição que sucede no discurso antijesuíta é o uso da mesma palavra na continuidade temática do texto. Não há dúvida de que a repetição não é uma pobreza lexical, mas representa uma intenção do autor que assim exprime uma unidade textual, elogiando ou criticando certos elementos e, ao mesmo tempo, sublinhando a sua importância. Observemos um fragmento em que a palavra obediência passa a ter um caráter axiológico, sendo o significado religioso que esclarece o seu valor na doutrina jesuíta:

Fortaleceo [sic] S. Ignacio o voto de obediencia [sic] com a Auctoridade [sic], a Magestade [sic] de Deos [sic], como com huma [sic] arma invencivel [sic]: desterrou para longe da Companhia de seus filhos a vontade, e o juizo proprio [sic], que sam [sic] os dois mais perigosos inimigos da obediencia [sic]. Se acontecer que algum ceda a estes perniciosos inimigos, o nosso Santo Patriarcha [sic] o não reconhece entre seus filhos; olha-o como a quem não tem a sagrada marca desta milicia. Pelo que entre nós a menor obrigação, ou o mais baixo grao [sic] de obediencia [sic], consiste em fazer o que se nos manda; ou, para o dizer melhor, não há obediencia [sic] quando aquelle [sic], que executa o que se lhe mandou, não conforma interiormente a sua vontade, ou o seu juizo com o pensamento, ou sentir de quem o manda. Requer de nós o nosso Santo em todas as occasioens [sic] huma [sic] especie de cegueira. Quer que em todos os preceitos dos nossos Superiores não olhemos, se não a Deos [sic], que he [sic] quem manda na pessoa delles [sic]: e dahi [sic] nasce a lei inviolavel [sic] da obediencia [sic], a que somos obrigados [...]. (Rodrigues 1761: 238-239)

Chega a ser a muitas críticas significativa a descrição da obediência jesuíta em que se opera uma tentativa de rejeição. Não se trata, desde logo, de invocar as referências elogiáveis, ao gosto jesuíta; o que predomina são as coordenadas críticas de base antijesuíta. $\mathrm{O}$ fragmento, escrito por um geral da ordem, exprime a importância da obediência na doutrina jesuíta, sendo este mesmo utilizado na crítica antijesuíta. A palavra obediência aparece cinco vezes e intensifica a importância deste voto, apresentando-o com argumentos, explicando também o papel dos superiores e a necessidade de manter a obediência cega. $\mathrm{O}$ autor trabalha com base nos preceitos do género e a repetição das palavras parece surgir mais por desenvolvimento de componentes persuasivos. Destacá-lo do quadro semântico que o subordina, hipertrofiando a sua importância e conferindo-lhe um valor autossuficiente e uma linearidade de proselitismo só pode resultar, portanto, de uma ênfase entre aquilo que é emocional e racional. Isso é também o caso da carta de Catarina de Portugal que se prende com a função expressiva, repetindo palavras para transmitir a parte emocional. Vejamos pois o fragmento da carta da rainha que, mesmo como no fragmento anterior, a repetição da palavra compañia apresenta uma unidade textual, sublinhando a sua importância e, ao mesmo tempo, a parte emocional que assim é capaz de persuadir o leitor: 
¿La gloria y el servicio de nuestro Señor piden por ventura, que este Padre y su hermano tengan al Rey en esta esclavitud, y sean señores del reino? ¿Es el espiritu [sic] de la COMPAÑIA [sic] quien inspira este ardor por el gobierno, y da tanta ambicion [sic] de tener crédito en este mundo? ¿Es necesario para sus intereses escandalizar à [sic] los habitadores de todo un reino, y producir inumerables desòrdenes [sic] en el gobierno? ¿Es necesario sacrificar á [sic] tanta ambicion [sic] la honra de la COMPAÑIA [sic], el fruto que ella podria [sic] producir en las almas, y el consuelo que parece merecen [sic] mis años y mis aflicciones? ¿Pide el bien de esta COMPAÑIA [sic], que yo dege [sic] un reino, del que fui Reina, con el riesgo de ver nacer los mayores males? Ultimamente [sic], ¿es el interès [sic] de la COMPAÑIA [sic] el que me aparata de la sepultura del Rey mi señor y mis hijos, que están en la gloria, y quien me separa del Rey mi nieto, à [sic] quien tano ama mi corazon [sic]? (Centinela 1845: 39-40)

A rainha Catarina expressa partes emocionais e racionais da sua crítica, utilizando maiúsculas para sublinhar a importância da palavra compañia e, ao mesmo tempo, através da sua repetição, justifica a sua preocupação e o tema principal da sua carta. E é também a este nível que o problema da enumeração deve ser equacionado nas análises do discurso antijesuíta: evitando tomar os textos como expressão puramente estilística em relação ao tema e aos recursos estilísticos que os suportam; mas também sem esquecer a repetição das palavras que não se repetem sem um propósito discursivo, mas, além de uma função coesiva, justificam e transmitem o valor afetivo das palavras e expressões repetidas.

Existem outros tipos de repetições que aparecem no discurso antijesuíta e podiam ser analisados, mas, pelo menos, naquelas que acabamos de apresentar, mostramos como a coesão ajuda a reconstruir a imagem dos jesuítas portugueses, sendo a paráfrase e o paralelismo que aparecem nos textos escritos contra a Companhia de Jesus. A essa luz, por meio das análises dos recursos da repetição, somos capazes de decifrar o caráter de textos e palavras, mesmo como a intenção do próprio autor que pode utilizar certos recursos coesivos para influenciar ouvintes e leitores.

\subsection{Os recursos da substituição no discurso antijesuíta}

E chegamos aos recursos da substituição, porventura a recursos com os quais voltamos a mencionar o mesmo ou a atribuir as mesmas propriedades de palavras ou expressões referenciais. Chegamos a aquela parte de linguística em que o locutor exerce a atividade de linguagem, tendo um conhecimento das regras da língua (competência linguística), graças ao qual é capaz de reconhecer, compreender e construir frases gramaticais, exprimindo também o seu modo de ser. Não será necessário ir mais longe se quisermos detetar, desde logo, a importância da substituição das palavras nos textos antijesuítas, sendo este efeito que nos pode ajudar a analisar a imagem dos jesuítas na sociedade portuguesa.

A noção da substituição, em nossa opinião, é importante na construção da representação dos inacianos, fazendo parte da categoria linguística que se prende com a coesão e a coerência. E neste caso se revela de primordial importância a questão do recurso coesivo da substituição, ou seja, da colocação de uma palavra no lugar de outra, tendo o mesmo valor. Trata-se, no fundo, de sublinhar que qualquer palavra poder ser substituída por um advérbio, por um pronome ou por outra 
palavra da mesma categoria semântica. E, através da substituição, é indesmentível que o léxico desempenha um importante papel na visão dos jesuítas, sendo ela que aumenta o valor negativo de expressões no discurso crítico contra a Companhia de Jesus. De facto, a linguista Irandé Antunes fala sobre dois tipos da substituição: gramatical e lexical (Antunes 2005: 86). Por isso, no quadro da substituição em que uma palavra equivale à outra, os nossos estudos da noção dos recursos coesivos do discurso antijesuíta em Portugal tornam-se indispensáveis, sublinhando o léxico e as expressões antijesuítas. E é esse léxico e são essas expressões que chamam a nossa atenção, porque, através da substituição das palavras, podemos analisar o vocabulário relacionado com os jesuítas e assim reconstruir melhor a sua imagem na sociedade portuguesa da época.

Comecemos pois com a substituição gramatical em que os termos podem ser substituídos por pronomes, ou seja, por palavras que se empregam em vez de grupos nominais. Além disso, são os pronomes que referem aos participantes do discurso, constituindo, como sublinha Antunes, «uma classe particular de expressões referenciais, isto é, de expressões pelas quais nós nos referimos às coisas ou às pessoas» (Antunes 2005: 86). Compreenderemos ainda melhor a substituição gramatical relembrando dois modos da substituição pronominal: a anáfora e a catáfora. A primeira delas, através de um pronome, substitui uma palavra introduzida no mesmo texto. A segunda utiliza um pronome que refere a outra palavra introduzida posteriormente. Vejamos os exemplos destas substituições pronominais nos textos antijesuítas:

Affastam [sic] os homens pela mais escrupulosa, e perigosa parte dos seus animos[sic], que he [sic] a consciencia [sic]: batem-os com a opinião de Religião; e os surprendem [sic] quando os mesmos homens vão ter com elles [sic], quando lhes descobrem os seus pensamentos mais secretos, e lhes pedem conselho, e consolação. (Rodrigues 1761: 32)

Somos obrigados com grande mágoa nossa a nos pormos [sic] á lerta [sic], a nomear, e temer aquelles mesmos que, debaixo da aparrencia [sic], por huma [sic] nova especie, e ordem de Religião; e debaixo da capa, e nome glorioso, e santo de Jesus; não sómente [sic] tem [sic] feito huma nova Ordem, e Sociedade, contra a prohibição [sic], posta pela tão celebre Concilio [sic] de Latrão, convocado em 1215;.... mas são tanto mais para temer, e accusar [sic], quanto debaixo de huma [sic] capa tão santa, tão pia, e tão devota, e debaixo deste santo nome de Jesus, nos tem [sic] dividido [...]. Sabemos muito bem que estes novos profetas, estes novos adoladores da Curia Romana, os Jesuitas, foram os unicos [sic] que lansaram [sic] esta semente de scisma [sic], do erro, e da pertinaz controversia entre nós [...]. (Rodrigues 1761: 38-39)

No primeiro fragmento da carta antijesuíta escrita por um bispo, o termo os homens aparece em primeiro lugar e logo depois é substituído por pronome, referindo aos participantes do discurso. Sabemos bem que a anáfora se amplia em qualquer discurso, abrangendo sistemas da substituição pronominal de diferentes nomes do mesmo texto. Além disso, segundo Antunes, é preciso ver a substituição pronominal em qualquer texto como «ligação entre seus diferentes segmentos, possibilitando uma reiteração, a continuidade que o texto exige para ser coerente» (Antunes 2005: 87). No segundo fragmento de um procurado geral do parlamento de Tolosa, assistimos a uma catáfora com a qual, em primeiro lugar, aparece o pronome aquelles que refere ao termo jesuítas, introduzido posteriormente. Nesta medida, e não perdendo de vista o conceito da catáfora, importa 
sublinhar que a substituição não é apenas um dos recursos coesivos, mas também uma forma expressiva de caráter emocional-afetivo. É que, como lemos no fragmento, o pronome demonstrativo tem um caráter negativo, sendo utilizado para não nomear claramente os jesuítas, enumerando, em primeiro lugar, tudo aquilo que os pode caracterizar como hipócritas e pessoas que dividem a sociedade da época. Mas para esclarecer algumas substituições pronominais, analisemos outro fragmento do texto antijesuíta, ensinando nele a importância dos pronomes na coesão textual:

Primeiro grao [sic] de orgulho, que he [sic] a curiosidade, que os move a se introduzir em toda a parte, e maiormente nos confessionario [sic], para saber dos penitentes tudo, que se passa nas suas casas entre seus filhos, os seus domesticos [sic], e as outras pessoas, que ahi [sic] moram, ou ahi [sic] vão, e da mesma sorte no bairro: Curiosidade capaz de produzir os peiores [sic] efeitos. Se confessam hum [sic] Principe [sic], fazem-se senhores do governo de todo o seu palácio [sic]. Tambem [sic] querem governar-lhe os seus Estados, fazendo-lhe crer que nada lhe fahria [sic] bem, sem o seu cuidado, ou a sua industria [sic]. (Rodrigues 1761:33)

Inspirando-se nas análises de Irandé Antunes, observemos pois o fragmento da carta do papa Clemente VIII, analisando brevemente alguns pronomes que referem às coisas ou às pessoas do mesmo texto. No fragmento da carta, encontramos treze pronomes e dois advérbios que substituem um determinado termo. Os pronomes os, se, se, seu, sua referem aos jesuítas; os pronomes suas, seus, seus retomam a referência feita a penitentes; os pronomes seu, lhe, seus, lhe, lhe referem ao príncipe; os dois advérbios ahi referem às casas dos penitentes. Entre os termos e os outros termos que os substituem existe um nexo coesivo, formando uma cadeia que Irandé Antunes chama a «cadeia coesiva» (Antunes 2005: 91) que também aparece no fragmento da carta (p.ex. governar-lhe os seus Estados). Além disso, o uso dos pronomes, em nossa opinião, pode desempenhar uma função apelativa, utilizando a substituição pronominal em função de certo alerta. É que o autor emprega mais os pronomes que retomam a referência aos outros (penitentes e príncipes), como se quisesse sublinhar aqueles que são mais importantes e correm risco e, por meio do uso dos pronomes possessivos, criticasse o orgulho e a cobiça jesuíta (pode observar-se a relação dos pronomes possessivos com o verbo transitivo possuir e relacionar o seu uso com o texto). Mas além da substituição gramatical que pode desenvolver a crítica antijesuíta, os pronomes comparecem a si mesmos, orientando a sua estrutura e estabelecendo as expressões referenciais, sendo a seleção dos pronomes que pode decifrar o caráter do texto.

A somar brevemente a substituição gramatical nos textos antijesuítas, existe ainda outra particularmente importante, aquela que toca mais de perto a uma unidade lexical: a substituição lexical. É que a substituição de um vocábulo por outro produz a ligação de vários segmentos textuais e, através de ela, inter-relaciona, determina e qualifica o texto e os agentes da comunicação. Na medida em que equivale um termo a outro, o processo da reiteração, em geral, tem que conduzir-se por normas de interpretação e de análise textuais que se repercutem na observação das transformações lexicais do texto, das relações de sentido que as unidades lexicais estabelecem entre si e até da seleção lexical que exprime a atitude do locutor em relação ao seu próprio objetivo. Nesse sentido, pretendemos sublinhar que a substituição adiciona uma informação com a qual o sujeito falante revela, através de seleções lexicais, o seu conhecimento e as suas opiniões acerca de uma referência já inserida. 
De entre as substituições implicadas no vasto processo da coesão textual, avulta desde logo o sinónimo, enquanto substituição vinculada a uma palavra que, por ter um sentido próximo do de outra, pode ser empregada no mesmo texto. Com base na repetição de palavras, pode assim concluir-se que, para além de uma substituição, o sinónimo envolve a continuidade do tema do texto, que diz respeito ao assunto de que se trata. Além disso, a substituição serve para preservar a referência já introduzida, conservando na memória o objeto em questão. Estamos assim, deste modo, em condições de matizar o caráter informativo do texto e as suas habilidades para persuadir, afirmando que a substituição, como sublinha Antunes, pode também «elevar o grau de interesse do interlocutor pela forma como as coisas são ditas» (Antunes 2005: 100). Vejamos como a substituição do termo jesuítas marca o tópico e informa acerca destes religiosos, tentando persuadir ouvintes e leitores:

Ainda que os Jesuitas se não comprehendam [sic] em huma [sic] das quatro Ordens mendicantes, com tudo tem [sic] feito que se lhes consedessem privilegios similhantes aos dos Mendicantes. Jactam-se dissto [sic] nos seus livros, e se servem delles [sic] em todas as occasiones [sic] opportunas [sic] .... Nunca quizeram [sic] tomar o nome da sua Cabeça, ou do Seu Fundador....escandalizam-se quando lhes chamam Iniguistas, ou Loiolistas, ou tambem [sic] Ignacianos; depois que mudaram o nome de Inigo, seu Fundador, em o de Ignacio [sic]. Não acham nome, que lhes seja tão honorifico [sic], como o de Companhia, ou Sociedade. (Rodrigues 1761: 91)

Da Companhia sahiram [sic] estes grandes homens, Soares, Vasques, Molina, e outros; que pela excellencia [sic] do seu juizo [sic], e da sua doutrina, extenderam os limites da sciencia [sic] sagrada, foram os ornamentos do nosso seculo [sic], e serão a admiração da posteridade. (Rodrigues 1761: 248)

Este novo mundo, que com titulo [sic] especial, arrogante e ambicioso, se diz que he [sic] a Companhia de Jesus, não deve ser admittido [sic] ao corpo da nossa Universidade; mas deve-se totalmente desnaturalizar [...]. (Rodrigues 1761: 9)

No fragmento da primeira carta que citámos, por um lado, a substituição do termo jesuítas tem um caráter explicativo e, por outro, chega a ser certa crítica da soberba destes religiosos com a qual o autor tenta convencer ouvintes e leitores, utilizando os sinónimos para esclarecer o objeto em questão. No segundo fragmento, escrito por um jesuíta e publicado no esboço antijesuíta como exemplo da soberba destes religiosos, podemos ver como a palavra homens é substituída por outras palavras como ornamentos, admiração de caráter metafórico. No terceiro fragmento, o termo novo mundo substitui a Companhia de Jesus, utilizando a palavra novo com a qual o autor como se quisesse chamar a atenção de ouvintes e leitores que deviam examinar cuidadosamente tudo o que é recente.

Lidas dentro do seu contexto, as palavras metafóricas remetem para o recurso expressivo que consiste em usar um termo com o significado de outro. A metáfora tem lugar certo na grande maioria dos textos jesuítas e antijesuítas e o seu uso explica-se, antes de mais, como forma de uma representação simbólica que melhor podia esclarecer o significado do termo. E não pode deixar de parecer altamente significativo que, mesmo junto com os sinónimos utilizados no conceito do 
antijesuitismo, o uso da substituição de uma palavra por outra de significado equivalente garante a continuidade textual e a sua compreensão.

Para além de exemplos de sinónimos que aparecem nos textos antijesuítas, a substituição lexical contempla ainda a presença de hiperónimos quando uma palavra se emprega ao significado geral da outra e hipónimos cujo significado está incluído na palavra de significado mais geral. A hiperonímia, como sublinha Antunes, é «uma relação entre um termo subordinado e um, outro superordenado» (Antunes 2005: 102). Observemos pois dois fragmentos dos textos antijesuítas, mostrando neles a presença de um hiperónimo e hipónimo:

Vós vos fingieis [sic] pobres, ainda que na realidade fosseis ricos. Esta reprehensão [sic], segundo S. Bernardo, convém perfeitamente a Religiosos, que, fazendo voto de pobreza, querem possuir grandes riquezas, e não necessitar de nada. $\mathrm{He}$ [sic] por ventura difficultoso [sic] ver quanto isto he [sic] proprio [sic] dos Jesuitas? Elles [sic] se chamam pobres: em toda a parte dizem que o sam [sic]: querem que os acreditem; e com tudo sam [sic] mais ricos, do que todos os outros Religiosos juntos. (Rodrigues 1761: 98)

Tendo ouvido que contra o ultimo [sic] Acordam do Concelho de Estado, que reprimio [sic] as violencias [sic] dos Jesuitas...se preparam estes Padres para tornar a começar os seus combates com mais aperto, que nunca [...]. (Rodrigues 1761: 143)

No fragmento da primeira carta, vemos a relação que se estabelece entre o termo superordenado Religiosos (hiperónimo) e o termo subordinado Jesuitas, sendo o uso destas palavras junto com a crítica da riqueza que excitam o leitor (os religiosos deviam ser pobres, mas os jesuítas violam essa tradição). No segundo fragmento, a palavra de significado geral Padres substitui a palavra Jesuitas (hipónimo), provocando também certa polémica (os Padres não deviam ser violentos, mas os jesuítas são vistos como aqueles que exercem violência). O hiperónimo e o hipónimo que acabamos de citar passam a ser um tipo de oximoro que reúne, no mesmo conceito, palavras de sentido contraditório, influenciando assim a opinião do leitor e levando-o ao campo do antijesuitismo. Certamente por ser mais usado em textos, o hiperónimo aparece mais no discurso antijesuíta do que os sinónimos, sendo essas palavras de significado geral que podem substituir outras mais específicas, jogando com o seu próprio significado no conceito da intenção da sua colocação.

Com base nas análises dos hiperónimos, podemos ver como este tipo da substituição se junta com a crítica antijesuíta em que, como lemos nos fragmentos, se sublinha a cobiça e certas violências dos inacianos. Numa linha de dedução meramente linguística, poderia pensar-se que a substituição lexical faz parte de uma estratégia estilística do autor do texto. Mas não obrigatoriamente. Desde logo porque, segundo o nosso entendimento, a substituição lexical não configura um posicionamento claro a propósito de recursos estilísticos ou semânticos; em segundo lugar, porque o envolvimento intencional sobressai como tópico de referência, à luz do qual os textos críticos se transformam em esboços antijesuítas. 


\section{Conclusão}

Analisámos alguns recursos coesivos que aparecem nos textos antijesuítas em Portugal, seguindo as teorias da linguista Irandé Antunes. No conceito de procedimentos, dedicámo-nos à repetição e à substituição que, como dizíamos acima, são esses recursos que matizam o discurso antijesuíta. Com o uso de paráfrases e paralelismos somos capazes de decifrar o caráter dos textos antijesuítas, mesmo como a intenção do próprio autor. No âmbito da paráfrase que reformula a mesma informação, mesmo como no paralelismo ao que uma unidade semântica corresponde uma estrutura gramatical, analisámos a imagem dos jesuítas que, como vimos nos fragmentos do discurso da época, são vistos como religiosos desobedientes ou cobiçosos, sendo a repetição de palavras que intensifica a parte emocional do discurso e assim pode persuadir melhor ouvintes e leitores.

Ao estudar sumariamente a substituição gramatical e a lexical de alguns textos antijesuítas em Portugal, o mínimo que pode dizer-se é que o uso de sinónimos ou hiperónimos desenvolvia a crítica contra a Companhia de Jesus, sendo a substituição que adicionava certa informação com a qual os autores antijesuítas revelavam, através de seleções lexicais e gramaticais, a sua postura acerca da referência inserida, ou seja, acerca do mau comportamento dos jesuítas. As anáforas, catáforas, pronomes possessivos ou conjunções múltiplas de intensidade pertencem aos meios linguísticos de aplicação textual geral e não podem ser considerados sendo caraterísticas dos textos antijesuítas. Essas mesmas retomadas de termos também não podem servir para construir ou reconstruir a imagem dos jesuítas, mas indicam a prática discursiva na época e tornam intensa a crítica antijesuíta. Ao longo do artigo, através de análises da repetição e da substituição do léxico antijesuíta, revelamos o uso do léxico e da gramática que veiculam qualquer discurso, sendo, sobretudo, as formas de repetições e substituições que, dentro do conceito de caráter emocional-afetivo, reforçam a crítica antijesuíta.

\section{Referências bibliográficas}

Antunes, I. (2005). Lutar com palavras: coesão e coerência. São Paulo: Parábola.

Col. de autores (1845). Centinela contra Jesuitas y resumen de las causas de du engrandecimiento y corrupción.

Zaragoza: Roque Gallifa.

Fávero, L. L. (1991). Coesão e coerência textuais. São Paulo: Ática.

Fávero, L. L.; \& Koch, I. (1985). Revendo os critérios de textualidade. (Não publicado)

Halliday M. A. K.; \& Hasan, R. (1976). Cohesion in English. London: Longman.

Koch, I. (2014). O texto e a construção dos sentidos. São Paulo: Contexto.

Rodrigues, M. (1761). Retrato dos Jesuitas Feito ao natural pelos mais sabios e mais ilustres Católicos. Lisboa:

Officina de Miguel Rodrigues.

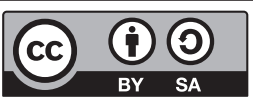

This work can be used in accordance with the Creative Commons BY-SA 4.0 International license terms and condition (https://creativecommons.org/licenses/by-sa/4.0/legalcode). This does not apply to works or elements (such as images or photographs) that are used in the work under a contractual license or exception or limitation to relevant rights. 